\title{
Perencanaan Instalasi Pengolahan Air Limbah Kegiatan Peternakan Sapi Perah dan Industri Tahu
}

\author{
Rahani Yunanda Kusumadewi dan Arseto Yekti Bagastyo \\ Jurusan Teknik Lingkungan, Fakultas Teknik Sipil dan Perencanaan \\ Institut Teknologi Sepuluh Nopember (ITS) \\ J1. Raya ITS Surabaya 60111 Indonesia \\ e-mail: bagastyo@enviro.its.ac.id
}

\begin{abstract}
Abstrak-Air limbah yang dihasilkan dari kegiatan peternakan sapi perah dengan diversivikasi industri tahu di Dusun Klagen, Krian, Kabupaten Sidoarjo memiliki karakteristik yang melebihi baku mutu. Kualitas air limbah kegiatan peternakan sapi diketahui mencapai 1.605,24 mgBOD/L, 4.134,35 mgCOD/L, dan TSS sebesar $1.170 \mathrm{mg} / \mathrm{L}$. Kualitas air limbah untuk kegiatan industri tahu diketahui sebesar $2.387,06 \mathrm{mg} / \mathrm{L}$ untuk BOD5 dan COD sebesar 4.204,2 mg/L, serta TSS sebesar $240 \mathrm{mg} / \mathrm{L}$. Melihat karakteristik tersebut diperlukan instalasi pengolahan air limbah (IPAL) agar air limbah yang dibuang ke badan air memenuhi baku mutu.

Perencanaan didasarkan pada karakteristik air limbah yang diperoleh dari hasil uji laboratorium dan kondisi eksisting lokasi studi. Alternatif pengolahan yang direncanakan adalah pengolahan dengan teknologi upflow anaerobic sludge blanket (UASB) dan kombinasi anaerobic aerobic filter. IPAL yang direncanakan membutuhkan luas lahan sebesar $297 \mathrm{~m}^{2}$. Luas lahan tersebut juga meliputi bak ekualisasi sebagai penunjang pengolahan upflow anaerobic sludge blanket (UASB). Biaya yang dibutuhkan untuk membangun instalasi pengolahan air limbah sesuai perencanaan sebesar Rp 1.663.183.000.
\end{abstract}

Kata Kunci- air limbah, industri tahu, peternakan sapi perah, upflow anaerobic sludge blanket (UASB).

\section{PENDAHULUAN}

$\mathrm{P}$ ENINGKATAN kesejahteraan masyarakat berdampak pada peningkatan kesadaran pentingnya pemenuhan gizi seimbang, yaitu dengan peningkatan konsumsi susu [1]. Hal tersebut menciptakan peluang bagi masyarakat dalam peningkatan ekonomi, yaitu dengan pengembangan peternakan sapi perah [2]. Salah satu peternakan sapi perah skala besar dengan jumlah sapi perah \pm 300 ekor berada di Krian, Kabupaten Sidoarjo. Pada usaha peternakan sapi perah tersebut terdapat diversifikasi kegiatan yaitu dengan adanya industri tahu. Air limbah dari kegiatan peternakan sapi perah dan industri tahu memiliki konsentrasi pencemar yang tinggi, sehingga diperlukan adanya instalasi pengolahan air limbah (IPAL). Undang-Undang Nomor 32 tahun 2009 menyatakan, bahwa setiap usaha diperbolehkan membuang limbah ke media lingkungan hidup dengan persyaratan memenuhi baku mutu lingkungan hidup.
Penentuan sistem pengolahan air limbah di dalam perencanaan ini dilakukan dengan memilih beberapa teknologi pengolahan sebagai alternatif. Pemilihan teknologi pengolahan air limbah yang paling tepat dari alternatif pada perencanaan ini mempertimbangkan aspek teknis dan aspek finansial. Aspek teknis dalam perencanaan memperhatikan kriteria desain pengolahan dan capaian hasil pengolahan yang memenuhi baku mutu. Aspek finansial yang dipertimbangkan adalah biaya investasi dan operasional, serta perawatan.

Berdasarkan karakteristik air limbah dan kondisi eksisting, maka teknologi pengolahan air limbah yang dapat digunakan adalah upflow anaerobic sludge blanket (UASB) dilanjutkan dengan kombinasi anaerobik-aerobik filter. UASB merupakan pengolahan anaerobik yang dapat mengolah polutan dengan beban organik yang tinggi [3]. Rangkaian pengolahan UASB dan kombinasi anaerobik-aerobik filter merupakan pengolahan dengan efisiensi penyisihan polutan yang tinggi.

\section{METODOLOGI PERENCANAAN}

\section{A. Pengumpulan Data}

Data yang digunakan dalam perencanaan ini adalah data primer dan data sekunder. Pengumpulan data bertujuan untuk mendapatkan data-data yang mendukung sebagai pertimbangan dalam melakukan perencanaan IPAL. Data primer merupakan data yang didapatkan melalui observasi lapangan secara langsung. Pada perencanaan ini, data primer yang dikumpulkan adalah debit air bersih kegiatan peternakan sapi perah, kualitas air limbah, ketersediaan lahan, dan kontur. Data sekunder dibutuhkan sebagai pelengkap data dalam melakukan perencanaan. Data sekunder yang digunakan antara lain debit air bersih industri tahu, baku mutu air limbah berdasarkan Peraturan Gubernur Jawa Timur No. 72 Tahun 2013, lokasi badan air penerima, dan harga satuan pokok kerja (HSPK) Kabupaten Sidoarjo 2016.

Debit air limbah pada perencanaan instalasi pengolahan air limbah (IPAL) ini terdiri dari debit air limbah dari kegiatan peternakan sapi perah dan industri tahu. Debit air limbah dari kegiatan peternakan sapi perah didapatkan dengan pengukuran secara langsung air bersih yang digunakan. Air limbah yang 
dihasilkan dari kegiatan peternakan sapi perah adalah $100 \%$ air bersih. Debit air limbah yang didapatkan untuk kegiatan peternakan sapi sebesar $302,40 \mathrm{~m}^{3} /$ hari. Debit kegiatan industri tahu didapat dari kapasitas pompa air bersih yang digunakan yaitu sebesar $360 \mathrm{~m}^{3} /$ hari untuk jam kerja yang dimulai pukul 08.00 - 16.00. Air limbah dari industri tahu sebesar $80 \%$ air bersih. Debit air limbah yang akan masuk ke dalam pengolahan merupakan air pencucian dan perendaman kedelai sebesar $\pm 15 \%$ air limbah [4]. Air limbah yang dihasilkan dari kegiatan industri tahu sebesar $43,2 \mathrm{~m}^{3} /$ hari.

Kalitas air limbah didapat dari sampling air limbah pada peternakan sapi perah dan industri tahu yang dilanjutkan dengan analisis laboratorium. Pengambilan sampel air limbah peternakan sapi perah dilakukan secara composite dan air limbah industri tahu dilakukan secara grab sampling. Pengambilan sampel air limbah dilakukan tiga kali pada jam kerja seluruh aktifitas di hari yang berbeda. Jumlah pengambilan sampel tersebut dianggap dapat mewakili karakteristik air limbah untuk setiap hari kerja. Parameter yang diperhatikan dalam perencanaan ini adalah BOD, COD, TSS, dan $\mathrm{pH}$ sesuai dengan baku mutu yang diacu. Baku mutu yang dijadikan acuan adalah Peraturan Gubernur Jawa Timur No. 72 Tahun 2013 untuk kegiatan industri pengolahan kedelai.

\section{B. Perencanaan Unit IPAL}

Perencanaan unit IPAL meliputi perhitungan dimensi UASB dan kombinasi anaerobik-aerobik filter. Sebelum masuk ke UASB, air limbah ditampung terlebih dahulu dalam bak ekualisasi kemudian dipompa untuk mengalirkan air dari bak ekualisasi ke UASB. Hal ini dikarenakan UASB sensitif terhadap variasi debit [3]. Diagram alir pengolahan dapat dilihat pada Gambar 1.

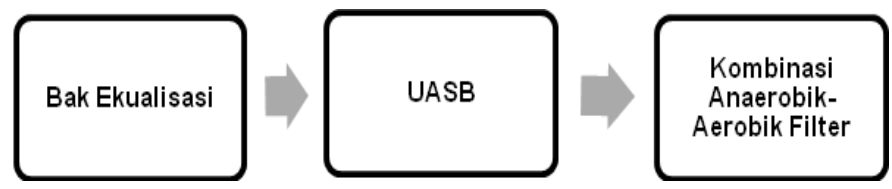

Gambar 1 Diagram Alir Pengolahan Air Limbah

Unit kombinasi anaerobik-aerobik filter memerlukan media filter untuk proses pengolahannya. Media yang digunakan sebaiknya media yang memiliki efektifitas yang baik. Efektifitas media dapat dilihat dari luas permukaan dan porositas media. Media yang digunakan pada perencanaan ini adalah sarang tawon berbahan plastik dengan luas permukaan $226 \mathrm{~m}^{2} / \mathrm{m}^{3}$ dan porositas $98 \%$ [5].

Setelah didapat dimensi unit-unit IPAL, dibuat gambar secara detail atau Detail Engineering Design (DED) yang dinyatakan dalam satuan meter. Selanjutknya dilakukan perhitungan biaya yang dibutuhkan untuk pembangunan IPAL. Perhitungan biaya mengacu pada Harga Satuan Pokok Kerja (HSPK) Kabupaten Sidoarjo Tahun 2016 yang dikalikan dengan volume pekerjaan.

\section{HASIL DAN PEMBAHASAN}

\section{A. Debit dan Karakteristik Air Limbah}

Debit dan karakteristik air limbah didapat berdasarkan datadata yang telah dikumpulkan. Karakteristik air limbah yang didapat dijadikan landasan peencanaan karena konsentrasi masing-masing parameter melebihi baku mutu. Debit dan karakteristik air limbah campuran kegiatan peternakan sapi perah dan industri tahu dan baku mutu dapat dilihat pada Tabel 1.

Tabel 1.

Karakteristik Air Limbah Campuran dan Baku Mutu

\begin{tabular}{ccc}
\hline \hline \multirow{2}{*}{ Parameter } & $\begin{array}{c}\text { Konsentrasi Air } \\
\text { Limbah }\end{array}$ & Baku Mutu Kegiatan Industri Tahu \\
\hline BOD 5 & $1702,97 \mathrm{mg} / \mathrm{L}$ & $150 \mathrm{mg} / \mathrm{L}$ \\
COD & $4143,08 \mathrm{mg} / \mathrm{L}$ & $300 \mathrm{mg} / \mathrm{L}$ \\
TSS & $1053,75 \mathrm{mg} / \mathrm{L}$ & $100 \mathrm{mg} / \mathrm{L}$ \\
pH & 8 & $6-9$ \\
Suhu (T) & $30^{\circ} \mathrm{C}$ & \\
Debit (Q) & $345,6 \mathrm{~m}^{3} /$ hari & \\
\hline \hline
\end{tabular}

\section{B. Hasil Perencanaan IPAL}

Hasil perhitungan dalam perencanaan instalasi pengolahan air limbah adalah sebagai berikut.

\section{Bak Ekualisasi}

Bak ekualisasi berfungsi mendapatkan debit yang stabil untuk keberhasilan pengolahan dalam UASB. Berdasarkan fungsi tersebut maka dalam bak ekualisasi tidak terdapat efisiensi penyisihan polutan. Air limbah yang ditampung dalam bak ekualisasi disalurkan ke unit UASB dengan pompa submersible. Waktu pemompaan direncanakan selama 24 jam, sehingga kapasitas pompa yang digunakan adalah 18,72 $\mathrm{m}^{3} / \mathrm{jam}$. Dimensi bak ekualisasi yang didapatkan adalah $5,9 \mathrm{~m}$ x $5,9 \mathrm{~m} \times 4 \mathrm{~m}$ dengan freeboard $0,5 \mathrm{~m}$. Gambar unit bak ekualisasi dapat dilihat pada Gambar 2.

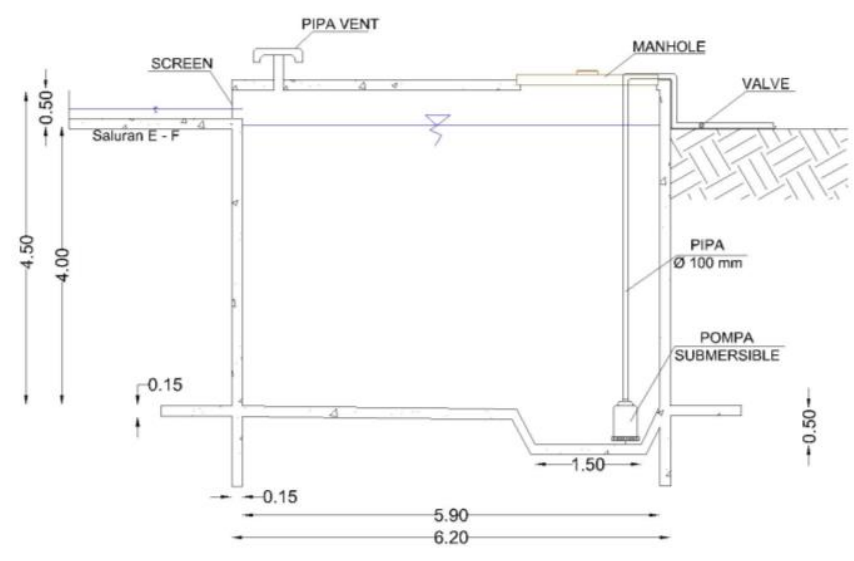

Gambar 2. Bak Ekualisasi

\section{Upflow Anaerobic Sludge Blanket (UASB)}

Upflow anaerobic sludge blanket (UASB) merupakan sistem pengolahan anaerobik di mana air limbah masuk dengan memanfaatkan aliran ke atas. Pengaliran air limbah tersebut menyebabkan terjadi kontak antara air limbah dengan 
lumpur sehingga terbentuk lumpur endapan. Pada perencanaan ini direncanakan UASB sebanyak satu reaktor dengan debit influen sebesar 18,72 $\mathrm{m}^{3} / \mathrm{jam}$. Upflow anaerobic sludge blanket (UASB) memiliki tiga zona yang terdiri dari zona pengendapan, zona transisi, dan digestion zone [6]. Volume zona pengendapan sebesar $15 \%$ - $20 \%$ dari volume total reaktor [7].

Perhitungan unit UASB dan kriteria desain mengacu pada literatur [8]. Kriteria desain yang diperhatikan dalam perencanaan unit UASB adalah:

- Organik loading rate $(\mathrm{OLR})=(5-15) \mathrm{kgCOD} / \mathrm{m}^{3} \cdot$ hari

- Hydraulic retention time $(H R T)=(4-8)$ jam

- Upflow velocity (vup) $=(0,8-1,25) \mathrm{m} / \mathrm{jam}$

Berdasarkan debit influen dan kriteria desain, maka dimensi unit UASB adalah 6,6m x 3,3m x 8m. Gambar desain UASB dapat dilihat pada Gambar 3 hingga Gambar 5. Pada perencanaan ini, tinggi total reaktor direncanakan $8 \mathrm{~m}$ yang terdiri dari $6 \mathrm{~m}$ tinggi proses reaktor, 1,5m tinggi gas liquid solid separator, dan $0,5 \mathrm{~m}$ tinggi clear zone. HRT efektif UASB berdasarkan dimensi yang diperoleh adalah 6,98 jam. OLR pengolahan pada UASB sebesar 14,24 $\mathrm{kgCOD} / \mathrm{m}^{3}$.hari. Kecepatan aliran ke atas $\left(\mathrm{v}_{\mathrm{up}}\right)$ dalam reaktor yang direncanakan adalah 0,86 m/jam.

Efisiensi penyisihan polutan pada UASB dihitung formula berdasarkan literatur [9]. Efisiensi penyisihan polutan sesuai perhitungan perencanaan adalah $82 \%$ untuk COD, $74 \%$ untuk $\mathrm{BOD}_{5}$, dan TSS sebesar 94\%. Pengolahan air limbah dengan UASB pada perencanaan ini menghasilkan lumpur dan gas methan. Lumpur yang dihasilkan sebesar $1,005 \mathrm{~m}^{3} /$ hari dengan solid retention time (SRT) 36,8 hari. Gas methan yang dihasilkan sebesar 455,29 $\mathrm{m}^{3} \mathrm{CH}_{4} /$ hari.

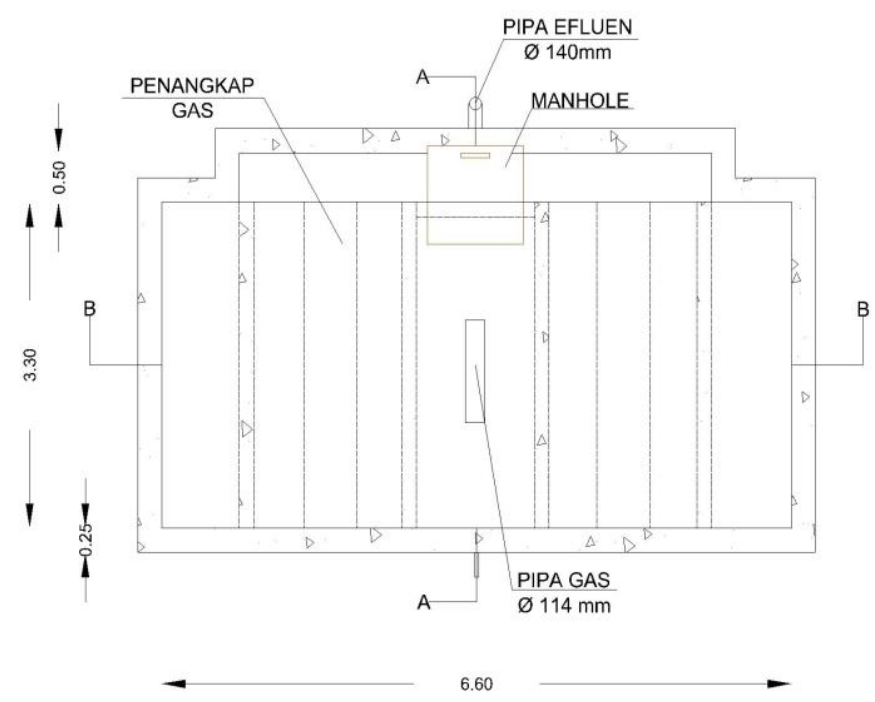

Gambar 3. Tampak Atas UASB

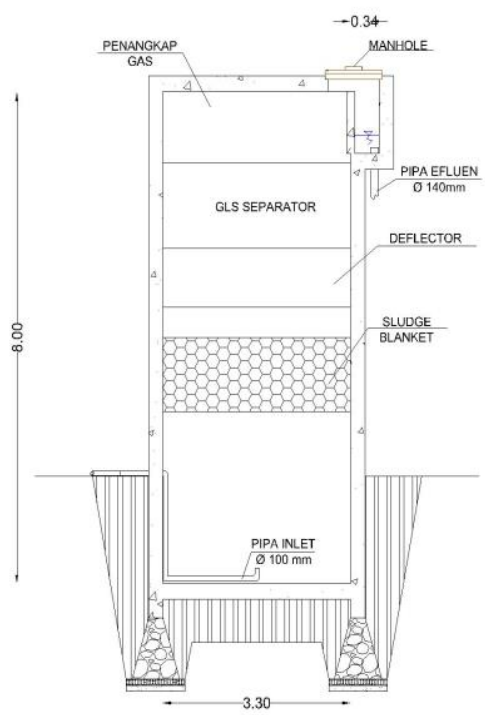

Gambar 4. Potongan A-A UASB

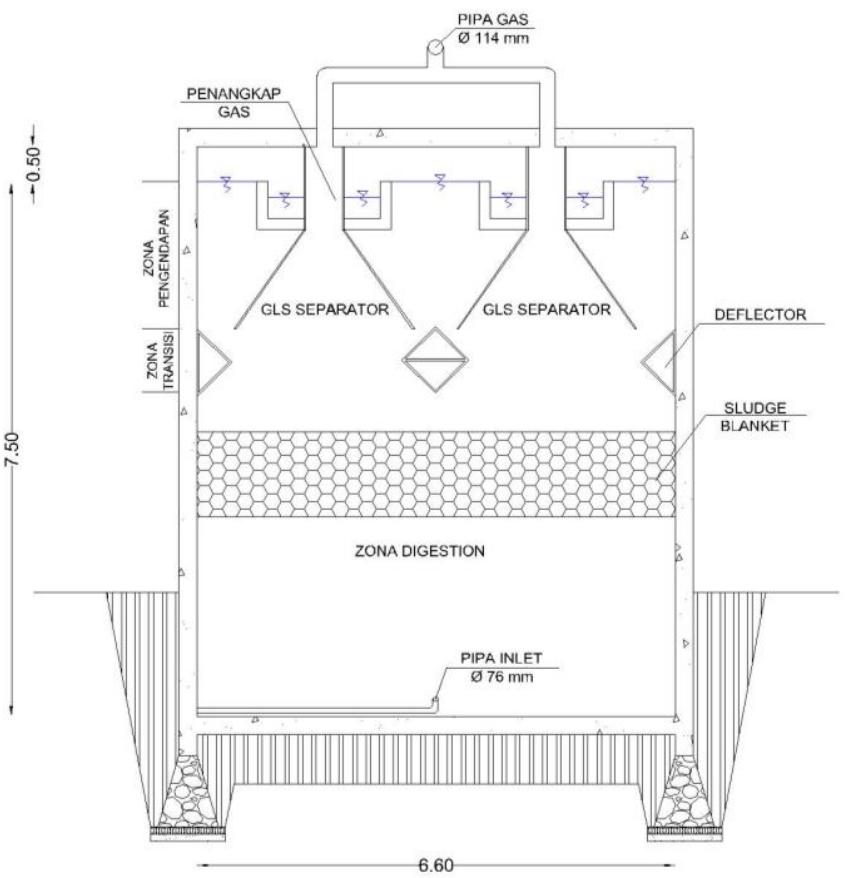

Gambar 5. Potongan B-B UASB

\section{Kombinasi Anaerobik-Aerobik Filter}

Unit kombinasi anaerobik-aerobik filter merupakan salah satu pengolahan biologis pertumbuhan melekat sehingga membutuhkan media. Pada perencanaan ini, unit kombinasi anaerobik-aerobik filter direncanakan dua reaktor yang disusun secara parallel. Debit yang masuk pada masing-masing reaktor adalah 224,64 $\mathrm{m}^{3} /$ hari. Kriteria desain dan perhitungan mengacu pada literatur [10]. Kriteria yang diperhatikan dalam perencanaan adalah:
- Organik loading rate $(O L R)=<4,5 \mathrm{kgCOD} / \mathrm{m} 3$.hari
- HRT anaerobik
$=(24-48) \mathrm{jam}$
- HRT aerobik
- Upflow velocity (vup) 
Setiap reaktor unit kombinasi anaerobik-aerobik filter yang direncanakan terdiri dari tiga kompartemen pengolahan anaerobik filter dan satu kompartemen aerobik filter. Dimensi setiap kompartemen sama, yaitu $3 \mathrm{~m}$ x 7,8m x $3 \mathrm{~m}$ dengan freeboard $0,3 \mathrm{~m}$. OLR pada pengolahan dengan unit ini adalah $1,297 \mathrm{kgCOD} / \mathrm{m}^{3}$.hari. Kecepatan aliran ( $\mathrm{v}_{\text {up }}$ ) maksimal adalah $0,41 \mathrm{~m} / \mathrm{jam}$. HRT untuk tiga kompartemen anaerobik adalah 24 jam dan untik anaerobik filter selama 7,5 jam. Pada kompartemen aerobik filter digunakan disk diffuser untuk menyuplai udara. Disk diffuser yang digunakan berkapasitas $11 \mathrm{~m}^{3} /$ jam sebanyak 5 buah tiap reaktor untuk memenuhi kebutuhan udara sebesar 1.242,73 $\mathrm{m}^{3} /$ hari. Gambar desain unit pengolahan ini dapat dilihat pada Gambar 6 hingga Gambar 9.

Efisiensi penyisihan polutan sesuai perencanaan adalah $82 \%$ untuk COD, $86 \%$ untuk $\mathrm{BOD}_{5}$, dan TSS sebesar $34 \%$ untuk kompartemen anaerobik filter. Efisiensi penyisihan polutan kompartemen aerobik adalah 10\% untuk COD, 7\% untuk $\mathrm{BOD}_{5}$, dan TSS sebesar $6 \%$. Pengolahan air limbah dengan kombinasi anaerobik-aerobik filter menghasilkan lumpur dan gas methan. Lumpur yang dihasilkan sebesar 4,06 $\mathrm{m}^{3} /$ hari untuk setiap kompartemen. Gas methan yang dihasilkan sebesar 34,49 $\mathrm{m}^{3} \mathrm{CH}_{4} /$ hari untuk setiap kompartemen.

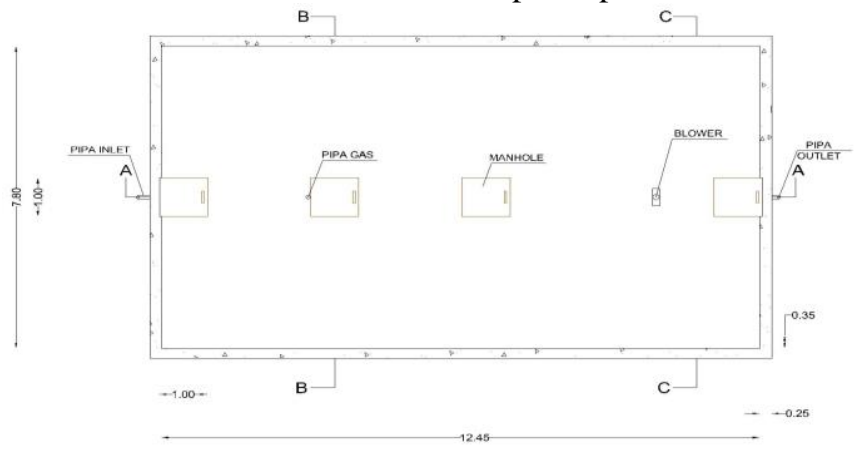

Gambar 6. Tampak Atas Kombinasi Anaerobik-Aerobik Filter

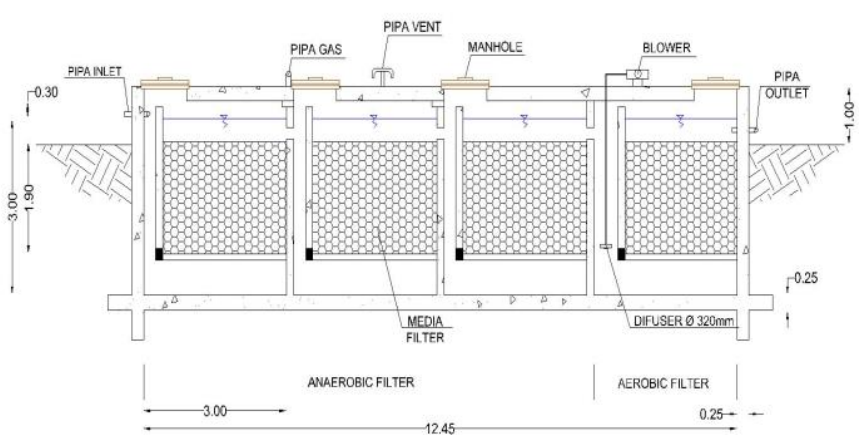

Gambar 7. Potongan A-A Kombinasi Anaerobik-Aerobik Filter

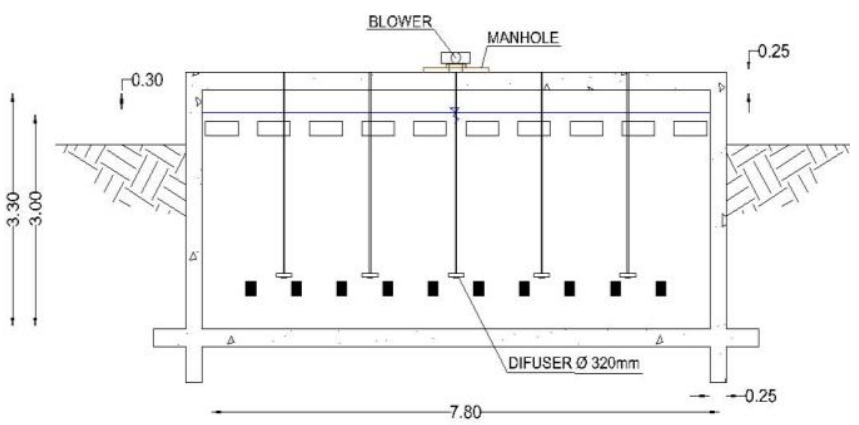

Gambar 8. Potongan B-B Kombinasi Anaerobik-Aerobik Filter

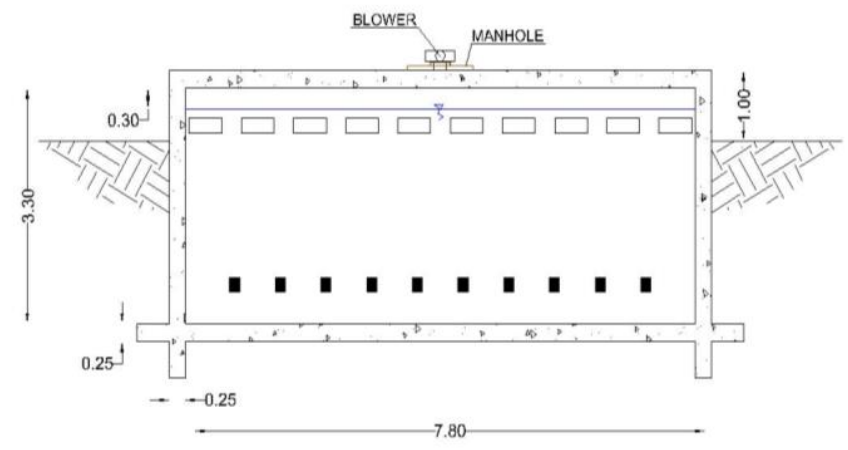

Gambar 9. Potongan C-C Kombinasi Anaerobik-Aerobik Filter

Kesetimbangan massa pada unit-unit pengolahan air limbah yang direncanakan dapat dilihat pada Gambar 10. Kesetimbangan massa digunakan untuk mengetahui proses dalam unit pengolahan dengan efisiensi penyisihan polutan.

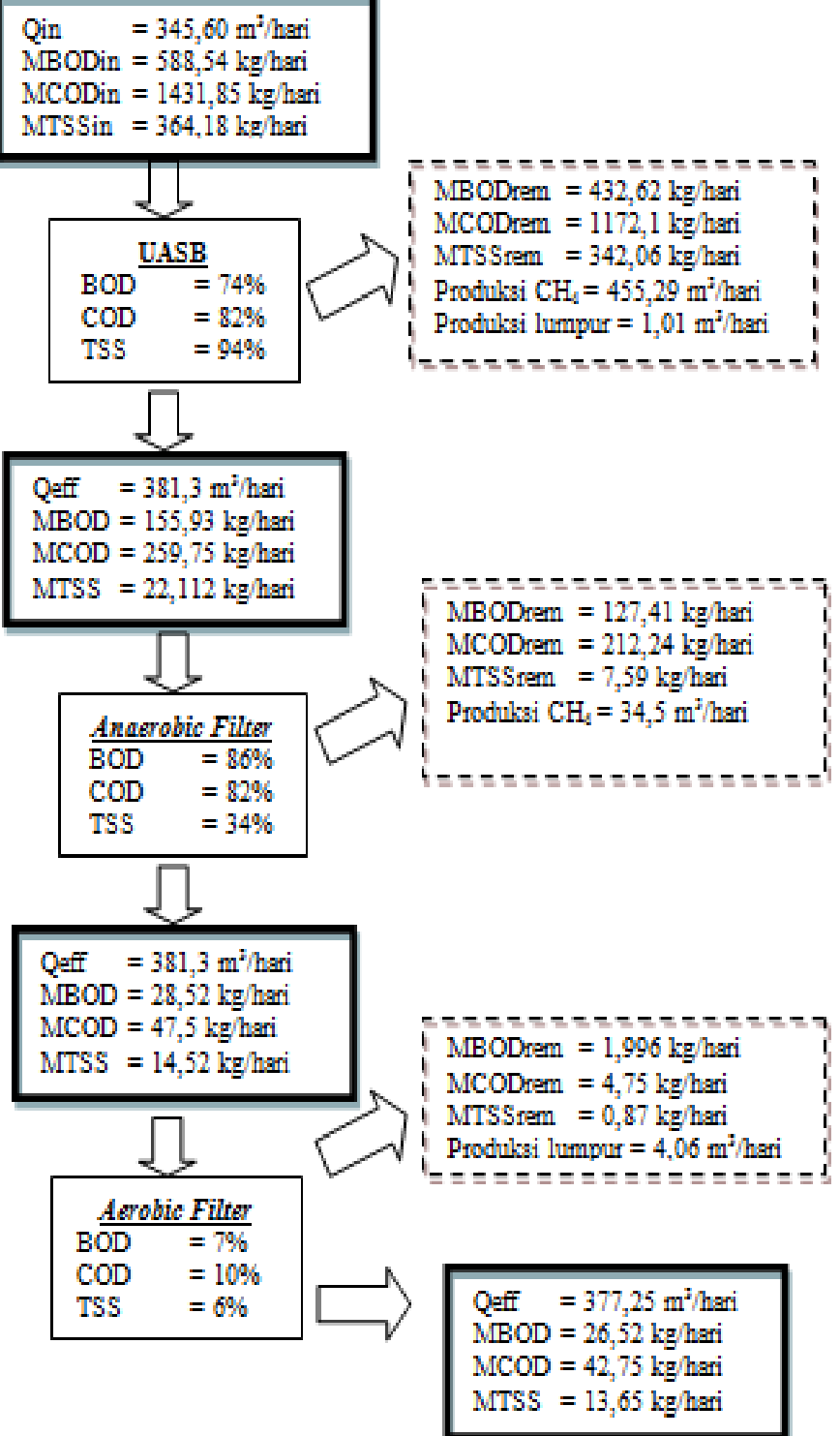

Gambar 10. Kesetimbangan Massa 


\section{DAFTAR PUSTAKA}

\section{Rencana Anggaran Biaya}

Perhitungan anggaran biaya disesuaikan dengan bill of quantity (BOQ) dalam perencanaan ini. Bill of quantity (BOQ) untuk setiap unit pada perencanaan ini dapat dilihat pada Tabel 2. Hasil perhitungan RAB dapat dilihat pada Tabel 3.

Tabel 2.

Bill of Quantity

\begin{tabular}{ccc}
\hline \hline Pekerjaan & Volume & Satuan \\
\hline & Bak Ekualisasi & \\
Pembersihan lahan & 43,784 & $\mathrm{~m}^{2}$ \\
Volume galian & 189,174 & $\mathrm{~m}^{3}$ \\
Pengurugan & 24,056 & $\mathrm{~m}^{3}$ \\
Pembetonan & 64,061 & $\mathrm{~m}^{3}$ \\
& UASB & \\
Pembersihan lahan & 33,000 & $\mathrm{~m}^{2}$ \\
Volume galian & 61,677 & $\mathrm{~m}^{3}$ \\
Pengurugan & 14,817 & $\mathrm{~m}^{3}$ \\
Pembetonan & 51,315 & $\mathrm{~m}^{3}$ \\
Pondasi batu kali & 4,5 & $\mathrm{~m}^{3}$ \\
Kombinasi Anaerobik-Aerobik Filter & \\
Pembersihan lahan & 220,692 & $\mathrm{~m}^{2}$ \\
Volume galian & 721,291 & $\mathrm{~m}^{3}$ \\
Pengurugan & 54,5514 & $\mathrm{~m}^{3}$ \\
Pembetonan & 155,287 & $\mathrm{~m}^{3}$ \\
Media filter & 277,575 & $\mathrm{~m}^{3}$ \\
Diffuser & 5 & $\mathrm{buah}^{3}$ \\
\hline \hline
\end{tabular}

Tabel 3.

Rencana Anggaran Biaya

\begin{tabular}{lll}
\hline \hline No & Uraian Pekerjaan & Jumlah Harga \\
\hline 1. & Pekerjaan Persiapan & 130.507 .604 \\
2. & Pekerjaan Konstruksi Bangunan & 1.488 .561 .915 \\
3. & Pekerjaan Pengadaan dan Pemasangan Pipa, & 35.324 .802 \\
4. Aksesoris, dan Perlengkapan Lainnya & 8.788 .679 \\
TOTAL BIAYA & Rp1.663.886.717 \\
\hline \hline
\end{tabular}

\section{KESIMPULAN}

Air limbah yang berasal dari kegiatan peternakan sapi perah dan industri tahu dapat diolah dengan UASB dan kombinasi anaerobik-aerobik filter. Berdasarkan hasil perencanaan diperoleh dimensi masing-masing unit IPAL adalah $5,9 \mathrm{~m} \mathrm{x}$ $5,9 \mathrm{~m} \times 4,5 \mathrm{~m}$ untuk bak ekualisasi, sebesar $3,3 \mathrm{~m} \times 6,6 \mathrm{~m} \times 8 \mathrm{~m}$ untuk UASB, dan 7,8m x $3 \mathrm{~m} \times 3,3 \mathrm{~m}$ untuk tiap kompartemen unit kombinasi anaerob-aerob filter dengan jumlah kompartemen 4. Berdasarkan dimensi tersebut, luas lahan yang diperlukan untuk konstruksi sebesar $297 \mathrm{~m}^{2}$. Biaya yang diperlukan untuk pembuatan IPAL sebesar Rp1.663.183.000.

\section{UCAPAN TERIMA KASIH}

Penulis mengucapkan terima kasih kepada pemilik peternakan sapi perah dan industri tahu yang berlokasi di Dusun Klagen, Krian, Kabupaten Sidoarjo atas izin yang diberikan untuk menjadikan lokasi usahanya sebagai lokasi studi dan data-data yang diberikan untuk perencanaan.
[1] Pusdatin, "Statistik Pertanian 2013." Pusat Data dan Sistem Informasi Pertanian, Kementerian Pertanian (2013) 316.

[2] M. Farid dan H. Suksesi, "Pengembangan Susu Segar Dalam Negeri untuk Pemenuhan Kebutuhan Susu Nasional." Buletin Ilmiah Litbang Perdagangan, 5 No.2 (2011).

[3] E.Tilley, L.mUlrich, C. LuethiI, P. Reymond, dan C. Zurbrueg, "Compedium of Sanitation System and Technologies," $2^{\text {nd }}$ Revised Edition. Duebendorf, Switzerland: Swiss Federal Institute of Aquatic Science and Technology (Eawag) (2014).

[4] I.G.A. Kusumawati, M.N. Cahyanto, dan E.S. Rahayu, "Modifikasi Pengolahan Limbah Cair Tahu di CV Kitagama Secara Anaerbik." Yogyakarta: Universitas Gadjah Mada (2011).

[5] N. I. Said, "Uji Performance Biofilter Anaerobik Unggun Tetap Menggunakan Media Biofilter Sarang Tawon untuk Pengolahan Air Limbah Rumah Potong Ayam,” Jurnal Air Limbah 1 (2005) 289 - 303.

[6] A. van Haandel, M.T. Kato, P. F. Cavalcanti, dan L. Florencio, "Anaerobic Reactor Design Concepts for The Treatment of Domestic Wastewater," Journal of Reviews in Environmental Science and Bio/Technology, 5 (2006) $21-38$.

[7] D. Mara, "Domestic Wastewater Treatment in Developing Countries." London: Earthscan (2004).

[8] Metcalf dan Eddy, "Wastewater Engineering: Treatment and Reuse Edisi IV." New York: McGraw Hill Inc (2003).

[9] C. Chernicharo,"Biological Wastewater Treatment Series." London: IWA (2007).

[10] L. Sasse, B. Gutterer, T. Panzerbieter, dan T. Reckerzügel, "Decentralised Wasterwater Treatment Systems (DEWATS) and Sanitattion in Developing Countries.” Bremen: BORDA (2009). 